\title{
A model for adaptive design
}

\author{
T. Willey \\ Department of 3D Design - Sustainable Practice, \\ University of Derby, UK
}

\begin{abstract}
There is an ever-increasing global imperative to investigate and utilise sustainable natural materials. This paper proposes a sequential model of design and construction which contends directly with this material category and, which itself, is drawn from natural systems of organisation and the principles of adaptation. The suggested model deals with the unexpected properties of natural materials and adapts to new possibilities which are surfaced through the design sequence itself.

The paradigms offered by orthodox design are largely predicated on material consistency - materials which can be described through a representational design-language. However, it is proposed that the inconsistencies and variables that are found in unrefined natural materials are not easily integrated into this process, and a new model is needed. It is also argued that the high level of material specification, which is a prerequisite of reproductability, has forced a dislocation between planning and doing - concept and activity. This is a bi-polar practice, which, although convenient for the mechanisms of industry, negates reflection and adaptation and denies the reiterative feedback loop, which is a salient feature of natural design systems.

Taking into account such models as reflective-practice and evolutionism, the proposed strategy is developed by incorporating the ecological concept of 'emergent properties', which, through its influential position within the schema, continually modifies both problem and solution.

Adaptive-design is described and as a cyclical sequence, which engages simultaneously with both the abstract and concrete domains of designing and constructing. The sequence is tested using case studies and finally, a visualisation tool is illustrated as a way of disseminating adaptive-design as model for practice.
\end{abstract}

Keywords: adaptive design, reflective practice, natural materials. 


\section{Introduction}

Typically, design has been defined as a plan of action - a preliminary plan for making something Thomson [1]. David Pye [2] suggests that design is what can be conveyed 'for practical purposes' through words and drawings. In such accounts the practice of design is regarded as separate from the 'making' process, and to a large extent relies on theoretical assumptions. Threedimensional design, when restricted to 'two-dimensional planning' is selfconstraining.

Whether it employs the drawn line, the written word or the digital image, it is a process predicated on symbolic and iconic relationships. It might be regarded as an analogue process as it shares only similar or corresponding attributes with the reality it represents. This Analogue approach is also restrictive in the sense that it fails to deal with inconsistencies typically found in natural (unrefined) materials. For instance, un-machined, unseasoned coppice wood is a material with so many dimensional and dynamic variables it would be impossible to simulate its characteristics through the icon and symbol of conventional design tools.

David Pye [2] makes a distinction between the 'workmanship of risk' and the 'workmanship of certainty' and argues that only direct practical involvement can take on the risks of variables and inconsistencies. Design, he argues (and here he is referring to conventional design practice), deals with certainties, 'In a designer's drawing all joints fit perfectly' [2, p.14]. It is this type of idealisation, and the associated pre-visualisation of ideal outcomes, that thwarts a flexible, adaptive response to design problems and as John Dewey suggests, analogue thinking is not an innate instinctive strategy: 'Animals learn (when they learn at all) by a "cut and try" method; by doing at random first one thing and another thing and then preserving the things that happen to succeed. Action directed consciously by ideas - by suggesting meanings accepted for the sake of experimenting with them...' Dewey [3]. This 'cut and try' approach when applied to design and construction would, by definition, bring together the processes of planning and doing. It would then be an undifferentiated and symbiotic activity, where actions would be directed by suggested understandings rather than idealised pre-visualisations. This is the basis for what will be called adaptive design, and upon which a new model of design practice is proposed.

\section{Evolutionism}

Magee [4] argues that in Karl Popper's 'evolutionism', the concept of origination, whether related to life, theories, or works of art, is not susceptible to rational explanation, and that the evolutionary process can have a 'rationale without there being... any overall plan or plot.' [4]. Popper also offers a theory of continuous development embodied in the following formula:

'where P1 is the initial problem TS is the trial solution, EE the process of error elimination applied to the trial solution and P2 the resulting situation, with new problems'. It is a feedback process where even 'failure to solve a problem 
teaches us something new about where its difficulties lie...and therefore alters the situation' [4, p.65]. Popper's formula demonstrates a continuous feedback loop between problem and acting on the problem, which has particular resonance for adaptive design; it is suggestive of an adaptive relationship between problem and solution; planning and doing; concept and activity.

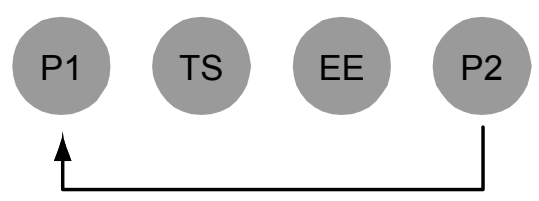

Figure 1: Popper's continuous development.

\subsection{Perceptual cycle}

In Neisser's perceptual cycle [5] a similar exchange relationship is expressed, where exploration samples information (object), modifies knowledge (the schema) and directs more exploration:

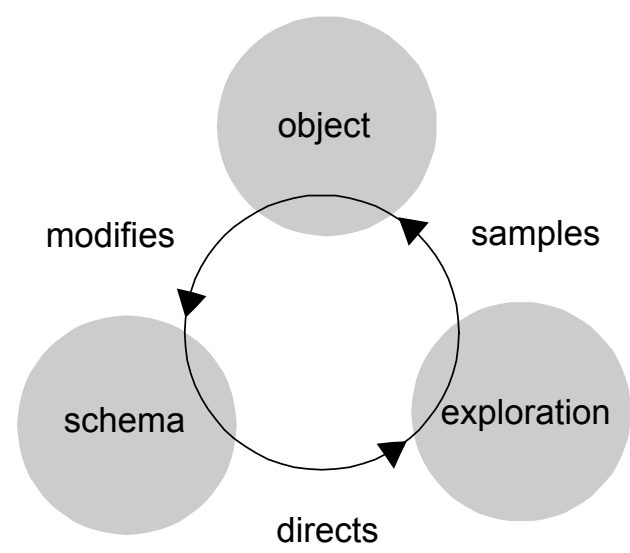

Figure 2: Neisser's perceptual cycle.

\section{Reflective practice}

Construction is essentially a practice-based activity and, like other practices, is susceptible to what Donald Schon describes as a 'dilemma' which is rooted in a particular epistemology of practice [6]. This dilemma - which Schon argues is endemic in academia and the professions - he describes as 'technical rationality' in which means are adjusted to ends through the application of science. It infers that deciding and creating (planning and execution) must be separated, as only deciding can be rationalised and approached with any degree of rigour. Schon argues [6] that the problem with this approach is that it cannot take into account what he calls the intermediate zones of practice such as: 
- uncertain situations, where you do not have a clear problem

- uniqueness, where the situation you have has never been seen before and may never be seen again

- conflict, where you can't adapt means to ends because they don't fit

\subsection{Reflection-in-action}

Schon suggests that to answer these problems a reflective approach is necessary which he calls 'reflection-in-action' or 'reflective practice'. Yoong [7] describes this simply as 'thinking about the action while you are doing it', or as Schon describes it, ...'our knowing is in our action' [8].

Brown and Duguid [9] have argued that there is a 'breach between learning and use, which is captured by the folk categories "know what" and "know how" [9] and that the meaningful acquisition of knowledge is at its best a process of 'situated cognition' - an activity contextualised and framed by 'authentic activity' [14]. They suggest that knowledge can be usefully regarded as a set of tools which are best understood through use: 'People who use tools actively rather than just acquire them,... build an increasingly rich implicit understanding of the world in which they use the tools and of the tools themselves. The understanding, both of the world and of the tool, continually changes as a result of their interaction'. Schon's reflection-in-action is a process which is predicated on situated cognition by acknowledging, describing and acting upon problematic situations as they develop through practice: 'As he tries to make sense of it, he also reflects on the understandings which have been implicit in his action, understandings which he surfaces, criticises, restructures, and embodies in further action'. Schon [8, p.50]

Schon introduces the concept of 'back talk' to describe something that is not anticipated but is revealed through practice. Scrivener [10] sees this as being central to the practice of the reflective practitioner who: 'will reflect-in-action on the situation's 'back talk', shifting stance as they do from "what if" to the recognition of implications, from involvement in the unit to consideration of the total and from exploration to commitment'. In forming the core of a design research methodology Scrivener suggests that reflection-in-action offers a 'paradigm of research within design' but acknowledges that we need to 'develop models for recording moments of reflection and the understandings implicit in the action...' [10].

What seems clear, is that 'understanding' and 'action' which are commonly regarded and interrogated as separate channels might, in relation to designing and constructing be best viewed (and practiced) as a simultaneous and symbiotic process.

In the transcription of the address to the Gulbenkian foundation, Craft as a Reflective Conversation with Materials [11] Schon relates his theory of reflective practice to the crafts. Referring to a particularly practical example (making a simple gate), Schon [11] applies a clearly defined sequence of reflection-inaction. This could be summarised as: 
- image of intention (the image of what I want to do)

- acting on the Image (start making)

- talk back of material (not anticipated)

- reflection (consider the new situation)

- restructuring of ideas (take advantage of the new situation)

\subsubsection{Reflective practice models}

Yoong [7] develops a reflective model from a number of his own case studies which makes use of prior experience to provoke new adaptations:

- intuitive signal or feeling

- take notice of signal

- make connections with prior experience

- consider adaptations

- assess the risk

- make adaptation

The context of prior experience is expanded by Mark Smith in Donald Schon: Learning Reflection and Change [12], here, Smith regards prior experience as a portfolio of memories from which one can build theories and responses: 'The ability to draw upon a repertoire of metaphors and images that allow for different ways of framing a situation is clearly important to creative practice and is a crucial insight.'

\section{A generic model of reflective practice}

A generic model of reflective practice was assembled and adopted for development through studio-based case studies. The model maintains the salient features common to reflective practice paradigms which are regarded as essential to the mechanism:

- problem

- frame problem

- reflection

- adaption

\subsection{Developing the model}

In developing the foundations of an adaptive design sequence, each key attribute of the generic model was rationalised and analysed in relation to both process and outcomes. This was achieved through practice-based case studies with undergraduate Sustainable-Design students tackling a wide range of design problems, but which particularly involve natural unrefined materials. Critically, the generic model was presented to practitioners as a cycle of practice with each stage transcribed in terms of workshop activity, thus: 
problem: the design brief, scheme of work or project

frame problem: the problem is approached by the physical activity of acting on materials

reflection: new properties are considered and unexpected outcomes are evaluated

adaptation: the question is asked, 'could this be new situation go some way in answering the problem?'

The process continues, with new discoveries (from acting on materials) being fed into the sequence, changing ideas about the problem and so suggesting further practical moves.

\section{A two domain model of adaptive design}

Following further case studies the adaptive design concept evolved. Critically, it was considered that the staging of the sequence (if only in the illustrated description) was not representative of the interrelationship of planning and execution (ideas and activity), which, as suggested at the beginning of this paper, was the driver towards a more adaptive model.

As these realisations began to emerge it became clear that a new two domain model (and a corresponding visualisation tool) should be considered, which would acknowledge the separation of the problem into two clear divisions the abstract 'concept' and the concrete 'actions' - parting ideas on solving the problem from the practical activity of working out the problem whilst clearly expressing the adaptive interrelationship.

The generic model of reflective practice provides the key for the new model but the formula is now predicated on four key components these being situated within two domains: (Concept) and (Actions/Materials/Properties):
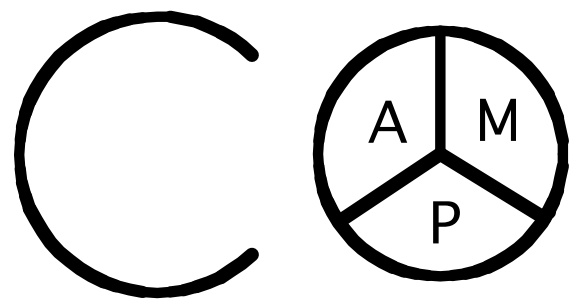

Figure 3: $\quad$ Two domain visualisation tool.

The concept can be regarded as the over-arching idea or as Schon puts it the image of intention' [11]. This is not an immutable constant in the sense of a fixed plan or visualisation, but rather a flexible open minded and reflective state, which responds to situations as they develop. 
Actions are the catalyst for interaction and, as they react with materials, represent the principal activity in the reflective design-construction sequence. They involve mechanical, and sometimes chemical, alteration of materials. Actions can be drawn from material-associated technologies which are purposefully assembled through investigation, they can already be part of the practitioner's repertoire, or they can be selected from any field of materiallybased practice. It is important for actions to be regarded as the act itself, dissociated from any particular material; in this sense actions become readily transferable and can be applied to any material as the basis for exploration.

Materials can be arbitrarily employed (selected without a particular reason), prescribed (as part of a design brief), or more usually, associated with the problem itself (being part of the context of the problem).

Properties are derived from the notion of 'emergent properties' a term often associated with ecology and ecosystems. Marten [13] defines an emergent property as a 'characteristic of a system as a whole that comes into existence from the organization of the system's parts rather than from the characteristics of any of the parts themselves'. As it relates to adaptive design, properties could be considered in much the same way, where the characteristics of the new situation (the result of acting on materials) are revealed to the practitioner as a set of new conditions with a range of new possibilities. Properties are often not anticipated and it is the unpredictability of the interrelating system which calls for reflective consideration, and through which new discoveries and understandings are made.

The cycle is essentially symbiotic. Acting on materials creates new properties that are reflected on and influence the concept, then these new conceptual realisations suggest further practical moves; and so on:

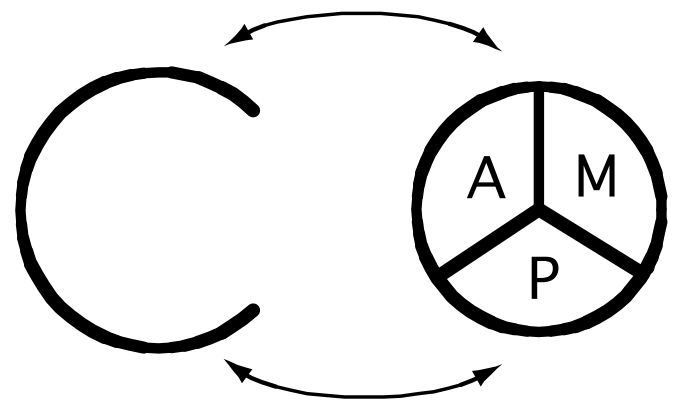

Figure 4: Symbiotic relationship of the two domains.

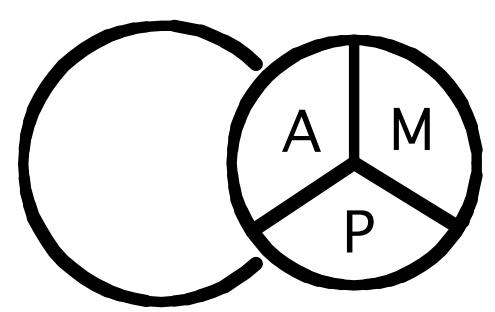

Figure 5: The cycle edges towards commitment. 
As the process continues, the conceptual domain becomes increasingly informed by activity - concept and activity adapt, and the domains are brought closer together. As they merge the process edges towards commitment.

And finally, as the problem reaches solution, the two domains are brought into coincidence. Activity and concept are completely co-adapted.

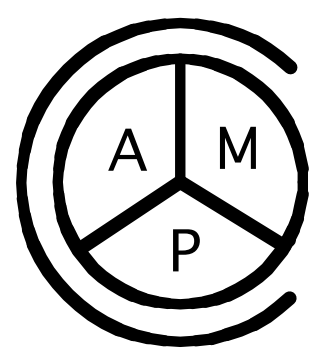

Figure 6: Activity and concept co-adapted.

\section{Conclusion}

Adaptive design is not a conventional strategy but in many ways it does mimic natural design systems. At risk of over simplifying - in natural adaptation processes the mechanisms of growth and evolution are subordinate to the environment, a tree for instance might have a guiding concept of what it wants to be (a straight tall plant) but in reaction to the environment it may find it needs to put in a bend or two.

The case studies show, that this adaptive capability is particularly useful when approaching specific types of design-problem: problems where the details are perhaps unclear and where unexpected situations can arise. These are the typical characteristics encountered when working with unrefined natural materials.

The adaptive design model has proved to be, not only a tool for solving design-construction problems, but has also acted as a catalyst for rapid innovation, that is, creating a new way of doing something in reaction to an 'onthe-spot' problem.

With this in mind, adaptive design might well be called upon to achieve what Papanek [14] calls 'optimum performance under marginal conditions', that is, in critical conditions where design and construction become more allied to survival than convenience. Here, adaptive design could make a significant contribution as a highly reactive strategy, which could be used 'out in the field' and in situations where conventional design would languish.

\section{References}

[1] Thomson, D; (ed). The Oxford Compact English Dictionary. Oxford University Press: Oxford, 1996.

[2] Pye, D; The Nature And Art Of Workmanship. Cambridge University Press: Cambridge, 1968. 
[3] Dewey, J; How We Think. Prometheus Books: New York, 1910.

[4] Magee, B; Popper. Fontana: London, 1973.

[5] Neisser, U; Cognition and Reality. W. H. Freeman and Company: San Francisco, 1976.

[6] Schon, D; Craft As A Reflective Conversation With Materials. Transcript of address: Gulbenkian Craft Initiative Furniture Forum, December 1986.

[7] Yoong, P; Towards A Model Of 'Reflection-In-Action': an analysis of facilitators' intuitive behaviours in electronic meetings. (online). www.lupinworks.com/ar/papers.html.

[8] Schon, D; The Reflective Practitioner. Arena: Aldershot, p.49, 1995.

[9] Brown, J \& Duguid, A; Situated Cognition; Columbia University. (online). http://www.ilt.columbia.edu/ilt/papers/JohnBrown.html.

[10] Scrivener, S; Design Research as Reflection On Action and Practice. Msc Research Methods in Design. Design Research Centre, University of Derby: Derby, 1999.

[11] Schon, D; Craft As A Reflective Conversation With Materials. Transcript of address: Gulbenkian Craft Initiative Furniture Forum, December 1986.

[12] Smith, M; Donald Schon: Learning, Reflection, and Change; Infed, Informal Education Encylopedia. (online). www.infed.org/thinkers/ etschon.htm.

[13] Marten, G; Human Ecology. Earthscan: London, pp. 43-45, 2001.

[14] Papanek, V; The Green Imperative. Thames and Hudson: London, p. 234, 1995. 